\title{
ENZYME VARIABILITY IN NATURAL POPULATIONS OF DAPHNIA CARINATA KING
}

\author{
PAUL D. N. HEBERT* and CHRISTOPHER MORAN*+ \\ School of Biological Sciences, University of Sydney, Sydney 2006, Australia
}

Received 18.xii.79

SUMMARY

\begin{abstract}
Fifteen populations of the cladoceran crustacean, Daphnia carinata, were examined for allozyme variation at sixteen gene loci. Individuals of this cyclic parthenogen were heterozygous at only $2 \cdot 1$ per cent of their loci. Large differences in gene frequencies existed among the populations. Within populations genotypic frequencies were in good agreement with Hardy-Weinberg expectations, and remained stable during annual cycles of population growth. Strong linkage disequilibrium was observed between the allelic variants at two leucine aminopeptidase loci in certain populations, suggesting that the loci are tightly linked and that populations of $D$. carinata are founded from few individuals.
\end{abstract}

\section{INTRODUCTION}

SEVERAL important invertebrate groups including rotifers, trematodes, aphids and cladocerans reproduce by cyclical parthenogenesis, but little is known about the genetic consequences of this mode of reproduction. As yet the cladoceran crustacean, Daphnia magna, is the only cyclic parthenogen whose population genetics has been investigated in detail. Among forty English populations of this species, allozyme variation was detected at 5 of the 15 gene loci examined (Hebert, 1975; Young, 1979). Microgeographical variation in gene frequencies was apparent and allelic substitutions were frequent between populations more than 100 meters apart. These substitutions were apparently the result of founder effect rather than natural selection (Hebert, 1975). Populations of D. magna were studied in two distinct environments-intermittent and permanent ponds. Populations in permanent habitats were able to reproduce by continued parthenogenesis with only sporadic sexual recruitment, while populations in intermittent habitats were regularly reestablished from sexual eggs. These two breeding systems have very different genetic consequences. In intermittent populations genotypic frequencies were in good agreement with Hardy-Weinberg expectations and they remained stable from one year to the next (Hebert, 1974a). By contrast, in permanent populations HardyWeinberg deviations were frequent and major shifts in genotypic frequencies were common (Hebert 1974b).

There remains a need to establish the generality of the observations made on $D$. magna. There have been studies on allozyme variation in other cladocerans-notably D. pulex (Berger and Sutherland 1978) and Simocephalus serrulatus (Smith 1974, Smith and Fraser 1976). The authors of

Present Addresses: * Department of Biology, University of Windsor, Windsor, Ontario, Canada N9B 3P4 and *+ Department of Animal Husbandry, University of Sydney, Sydney, N.S.W., Australia. 
these studies assumed that they were dealing with populations reproducing by cyclical parthenogenesis. However, they did not undertake any breeding studies, and more recent work on both $D$. pulex (Hebert and Crease, 1980) and $S$. serrulatus (P. D. N. Hebert, pers. obs.) has shown that many populations of these species reproduce by obligate parthenogenesis.

The current study had three aims - to estimate the amount of genetic variation present in natural populations of $D$. carinata, to determine the microgeographical pattern of this variation, and to analyze genotypic frequencies at individual loci in the populations. In the course of this work, an interesting case of linkage disequilibrium was detected.

\section{MATERIALS AND METHODS}

The Australian daphnid, D. carinata s.l. was, until recently, considered to be a single species showing cyclomorphic variation in head shape (Bayly and Williams 1973), but Hebert (1977a) has shown that it is a complex of at least nine species. The present study dealt only with populations of $D$. carinata s.s. The populations inhabited farm dams within a $20 \mathrm{~km}$ radius of Menangle, New South Wales-about $100 \mathrm{~km}$ southwest of Sydney. These dams were mostly less than 30 years old. They remained filled with water all the year round, but the populations of $D$. carinata in them were intermittent. Populations typically died out in early summer (December) and by late February active populations were invariably absent. The populations were reestablished from hatching ephippial eggs as the water temperature declined. Most populations reappeared in April or May so that populations reproduced parthenogenetically for a seven to eight month period each year.

Species of Daphnia reproducing by cyclical parthenogenesis produce both parthenogenetic and sexual eggs. The sexual eggs are enclosed within a protective structure known as an ephippium and must be fertilized if they are to develop. Some species such as $D$. middendorffiana and $D$. cephalata produce their ephippial eggs parthenogenetically-they are obligate parthenogens. Several lines of evidence indicated that $D$. carinata reproduced by cyclical parthenogenesis. Males were common in natural populations during periods of ephippial production and in the laboratory isolated females released ephippia with empty egg chambers. By contrast in cladoceran populations reproducing by obligate parthenogenesis, males are rare or absent during periods of ephippial production and females release unfertilized ephippial eggs. Breeding studies of allozyme variation at the PGI locus in $D$. carinata confirmed the fact that ephippial eggs were produced sexually, as segregation was observed among the ephippial progeny of heterozygous females.

Allozyme variation was detected using polyacrylamide disc electrophoresis. Specimens for analysis were stored alive at $5^{\circ} \mathrm{C}$ and used within four days of collection. The electrophoretic studies were carried out on single individuals. At least 48 individuals were analyzed from each population for the following enzymes-fumarase (FUM), glucose-6-phosphate dehydrogenase (G-6PDH), haemoglobin $(\mathrm{Hm})$, lactate dehydrogenase $(\mathrm{LDH})$, malate dehydrogenase $(\mathrm{MDH})$, phosphoglucose isomerase (PGI), tetrazolium oxidase (TO), alkaline phosphatase (ALK), esterase (EST), glutamate oxaloacetate transaminase (GOT), and leucine aminopeptidase (LAP). The last four enzymes were run on Tris-borate gels, while the other 
enzymes were run on Tris- $\mathrm{HCl}$ gels. A Tris-glycine electrode buffer was used for both types of gel. Gel buffers and staining procedures were similar to those described in Hebert (1972). Fifteen populations were screened for variation at all 16 loci and gene frequencies at the LAP-2 locus were determined in an additional 15 populations.

\section{RESUlts}

\section{(i) Electrophoretic phenotypes}

The phenotypes of FUM, ALK (2 loci), LDH (2 loci), G-6PDH, MDH, TO, XDH, HM, GOT, and EST (2 loci) were invariant among individuals from all populations. Three leucine aminopeptidase loci were scored. LAP-3 was invariant in all populations, but two alleles were present at the LAP-1 locus and three at the LAP-2 locus. Homozygotes at each locus had a single zone of enzyme activity and heterozygotes two zones, indicating that the functional enzyme was a monomer (fig. 1). Breeding studies indicated that allozyme patterns at both loci were heritable-parthenogenetic offspring invariably had the same allozyme phenotype as that of their mother. Two alleles were present at the PGI locus. Homozygotes had a single banded phenotype, while heterozygotes had a triple-banded phenotype, indicating that the functional enzyme was a dimer (fig. 1).

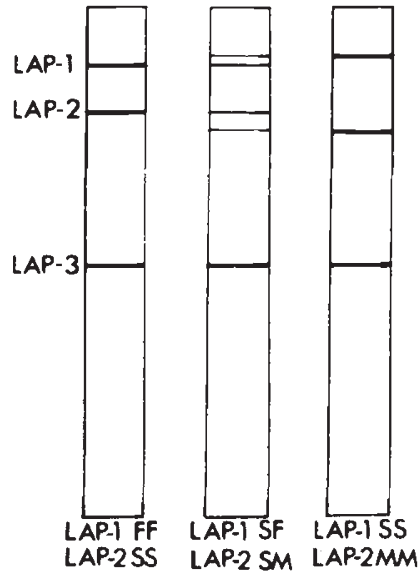

LAP
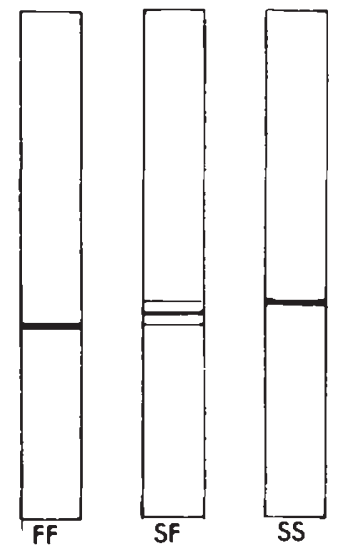

PGI

FIG, 1.-Allozyme phenotypes in Daphnia carinata at the phosphoglucose isomerase and leucine aminopeptidase loci.

\section{(ii) Gene frequencies in the populations}

Of the 30 populations surveyed for variation at the LAP-2 locus, six were fixed for the $S$ allele, seven were fixed for the $M$ allele and 16 were segregating for these two alleles. The remaining population was polymorphic for all three alleles (fig. 2). Differences in allele frequencies among populations were also detected at the PGI and LAP-1 loci (table 1). Twelve 


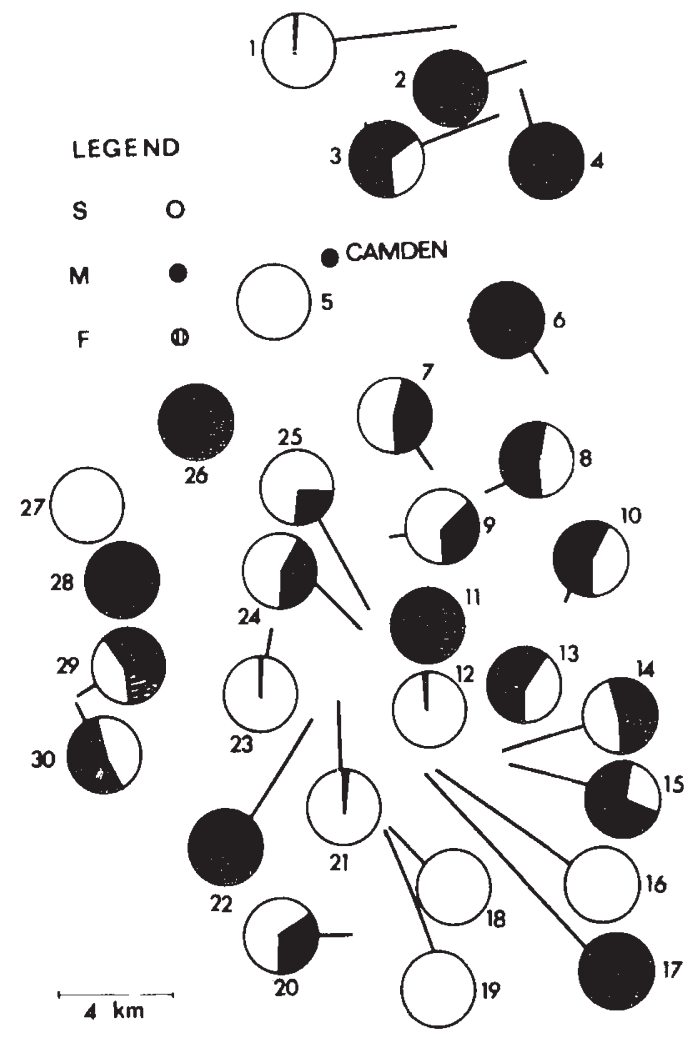

FIG. 2.-Gene frequencies at the LAP-2 locus.

TABLE 1

Genotypic frequencies at the 3 polymorphic loci in 15 populations of Daphnia carinata near Camden, N.S.W.

\begin{tabular}{|c|c|c|c|c|c|c|c|c|c|c|c|c|}
\hline \multirow{2}{*}{$\begin{array}{c}\text { Population } \\
\text { No. }\end{array}$} & \multicolumn{4}{|c|}{ LAP-1 } & \multicolumn{4}{|c|}{ LAP-2 } & \multicolumn{4}{|c|}{ PGI } \\
\hline & $\mathrm{n}$ & $S S$ & $S F$ & $F F$ & $n$ & $S S$ & $S M$ & $M M$ & $\mathrm{n}$ & $S S$ & $S F$ & $F F$ \\
\hline 1 & 48 & $1 \cdot 00$ & & & 60 & 0.96 & 0.02 & 0.02 & 48 & & & $1 \cdot 00$ \\
\hline 2 & 48 & $1 \cdot 00$ & & & 48 & & & $1 \cdot 00$ & 48 & & & $1 \cdot 00$ \\
\hline 5 & 96 & 0.07 & $0 \cdot 29$ & 0.64 & 48 & $1 \cdot 00$ & & & 72 & & 0.02 & 0.98 \\
\hline 10 & 48 & $1 \cdot 00$ & & & 138 & 0.06 & 0.34 & 0.60 & 48 & & & $1 \cdot 00$ \\
\hline 12 & 144 & & 0.16 & 0.84 & 93 & 0.92 & 0.08 & & 48 & & & $1 \cdot 00$ \\
\hline 13 & 48 & $1 \cdot 00$ & & & 89 & $0 \cdot 13$ & 0.54 & 0.33 & 48 & & & $1 \cdot 00$ \\
\hline 14 & 119 & 0.20 & 0.55 & $0 \cdot 25$ & 164 & $0 \cdot 32$ & $0 \cdot 42$ & 0.26 & 48 & & & $1 \cdot 00$ \\
\hline 15 & 112 & 0.20 & 0.40 & 0.40 & 143 & 0.49 & 0.45 & 0.06 & 48 & & & $1 \cdot 00$ \\
\hline 16 & 48 & 1.00 & & & 48 & & & $1 \cdot 00$ & 48 & & & $1 \cdot 00$ \\
\hline 17 & 48 & & & $1 \cdot 00$ & 48 & $1 \cdot 00$ & & & 48 & & & $1 \cdot 00$ \\
\hline 19 & 48 & & & $1 \cdot 00$ & 48 & $1 \cdot 00$ & & & 48 & & & $1 \cdot 00$ \\
\hline 21 & 48 & 1.00 & & & 93 & 0.83 & 0.17 & & 95 & 0.19 & 0.64 & $0 \cdot 17$ \\
\hline 27 & 48 & $1 \cdot 00$ & & & 48 & $1 \cdot 00$ & & & 48 & & & $1 \cdot 00$ \\
\hline 28 & 48 & $1 \cdot 00$ & & & 48 & & & $1 \cdot 00$ & 48 & & & 1.00 \\
\hline 29 & 96 & 0.82 & 0.18 & & $180^{*}$ & $0 \cdot 11$. & 0.33 & $0 \cdot 34$ & 162 & & $0 \cdot 36$ & 0.64 \\
\hline
\end{tabular}

* Population 29 also contained $M F, S F$ and $F F$ genotypes at frequencies of $0.16,0.06$ and $0 \cdot 005$, respectively. 
of the 15 populations were fixed for the $F$ allele of PGI, while three others were segregating. At the LAP-1 locus, eight populations were fixed for the $S$ allele, two for the $F$ allele, and five were polymorphic. The variance in allele frequencies among the populations was determined and used to calculate inbreeding coefficients $\left(F_{S T}\right)$ at each locus. At the LAP-2 locus the frequencies of the $M$ and $F$ alleles were pooled to simplify calculation of Wahlund's variance. The inbreeding coefficient was 0.75 at LAP-1, 0.60 at LAP-2 and 0.39 at the PGI locus.

\section{(iii) Genotypic frequencies}

In the five populations polymorphic for LAP-1 and in 14 of the 17 populations polymorphic for LAP-2, genotypic frequencies were in good agreement with Hardy-Weinberg expectations (tables 1 and 2). Significant

\section{TABLE 2}

Genotypic frequencies in 9 additional populations of Daphnia carinata polymorphic for $L A P-2$

$\begin{array}{crccc}\text { Population No. } & \mathrm{n} & \text { SS } & S M & M M \\ 3 & 143 & 0 \cdot 39 & 0.45 & 0 \cdot 16 \\ 7 & 77 & 0 \cdot 30 & 0.51 & 0 \cdot 19 \\ 8 & 42 & 0 \cdot 14 & 0.55 & 0 \cdot 31 \\ 9 & 139 & 0 \cdot 42 & 0.36 & 0.22 \\ 20 & 72 & 0 \cdot 81 & 0 \cdot 19 & - \\ 23 & 101 & 0.87 & 0 \cdot 10 & 0.03 \\ 24 & 144 & 0 \cdot 29 & 0.48 & 0.23 \\ 25 & 144 & 0.80 & 0 \cdot 20 & - \\ 30 & 96 & 0.18 & 0.48 & 0.34\end{array}$

heterozygote deficiencies were observed in the other three populations (Numbers 9, 14, 23) polymorphic for LAP-2. At the PGI locus, significant heterozygote excesses were present in two of the three polymorphic populations.

\section{(iv) Temporal surveys of genotypic frequencies at the LAP-2 locus}

In the Wedderburn Road population, genotypic frequencies (table 3 ) at the LAP-2 locus were stable throughout $1974\left(X_{6}^{2}=2 \cdot 71, p>0 \cdot 8\right)$. An excess of heterozygotes was noted in each of the individual samples, but this excess remained insignificant when the samples were pooled $\left(X_{1}^{2}=3 \cdot 42\right.$, $p>0.05)$. Genotypic frequencies in the single 1973 sample differed from those in the pooled 1974 sample $\left(X_{2}^{2}=32 \cdot 3, p<0 \cdot 001\right)$. The single 1973 sample from North Appin-1 contained a significant deficiency of heterozygotes, while all the 1974 samples had small heterozygote excesses. Genotypic frequencies were uniform throughout $1974\left(X_{6}^{2}=6.43, p>0 \cdot 3\right)$ but significantly different from those in $1973\left(X_{2}^{2}=12 \cdot 19, p<0 \cdot 001\right)$. Genotypic frequencies at North Appin-2 were also uniform throughout 1974 $\left(X_{4}^{2}=3.99, p>0.40\right)$, but significantly different from those observed in $1973\left(X_{2}^{2}=13 \cdot 75, p<0 \cdot 001\right)$.

\section{(v) Linkage disequilibrium}

When the allozyme phenotypes of individuals from the North Appin populations were determined, it was apparent that genotypes at the 2 LAP 
TABLE 3

Temporal analysis of genotypic frequencies at the LAP-2 locus in 3 populations of D. carinata

\begin{tabular}{lcrrrr} 
& & \multicolumn{4}{c}{ genotypic frequencies } \\
\cline { 3 - 6 } Population & \multicolumn{1}{c}{ Date } & $\mathrm{n}$ & $S S$ & $S M$ & $M M$ \\
Wedderburn Road & 15.11 .73 & 138 & 0.06 & 0.34 & 0.60 \\
(No. 10) & 29.04 .74 & 24 & 0.17 & 0.54 & 0.29 \\
& 03.06 .74 & 93 & 0.16 & 0.49 & 0.34 \\
& 02.07 .74 & 95 & $0 \cdot 11$ & 0.55 & 0.34 \\
North Appin-2 & 09.09 .74 & 70 & 0.16 & 0.59 & 0.26 \\
(No. 15) & 10.11 .73 & 143 & 0.49 & 0.45 & 0.06 \\
& $2-7.07 .74$ & 164 & 0.30 & 0.55 & 0.15 \\
& 09.09 .74 & 137 & 0.38 & 0.46 & 0.16 \\
North Appin-1 & 09.11 .74 & 141 & 0.39 & 0.46 & 0.15 \\
(No. 14) & 20.11 .73 & 164 & 0.32 & 0.42 & 0.26 \\
& 18.04 .74 & 35 & 0.29 & 0.57 & 0.14 \\
& 07.06 .74 & 119 & 0.20 & 0.55 & 0.25 \\
& 02.07 .74 & 86 & 0.16 & 0.57 & 0.27 \\
& 09.09 .74 & 91 & 0.15 & 0.52 & 0.33
\end{tabular}

loci were not randomly associated (table 4). Most individuals homozygous for the $S$ allele of LAP-1 were LAP-2-MM homozygotes, while most LAP-1 - FF homozygotes were homozygous for the $S$ allele of LAP-2. Individuals heterozygous at LAP-1 were usually also heterozygous at

\section{TABle 4}

Genotypic associations at the LAP-1 and LAP-2 loci in the North Appin populations

Two locus genotypes (LAP-1 genotype is first)

\begin{tabular}{crlrrrrrrrr} 
Population & Date & \multicolumn{1}{l}{ SSSS SSSM SSMM SFSS } & \multicolumn{1}{c}{ SFSM SFMM FFSS FFSMFFMM } \\
N.A.-1 & 7.6 .74 & - & 10 & 28 & - & 49 & 2 & 24 & 6 & - \\
& 2.7 .74 & - & 5 & 17 & - & 27 & - & 10 & 6 & - \\
& 9.9 .74 & 1 & - & 30 & - & 35 & - & 13 & 1 & - \\
N.A.-2 & $2-7.7 .74$ & - & 4 & 18 & - & 45 & - & 38 & 6 & 1 \\
& 9.9 .74 & 2 & 2 & 21 & 1 & 55 & - & 49 & - & 1
\end{tabular}

LAP-2. A few exceptions to this pattern were noted, confirming that 2 loci were involved. Maximum likelihood estimates of gametic frequencies were obtained using an algorithm based on Rust's (1972) method of Picard iteration (table 5). In both populations the coefficients of linkage disequilibrium were close to their maximum possible absolute value.

TABLE 5

Maximum likelihood estimates of gametic frequencies and of the coefficient of linkage disequilibrium in the North Appin populations. $\mathrm{D}^{\prime}=\mathrm{D} / \mathrm{D}_{\max }$

Two locus gamete frequencies

(LAP-1 genotype is first)

\begin{tabular}{cccccccc}
\cline { 6 - 8 } Population & Date & $S S$ & $S M$ & $F S$ & $F M$ & $D$ & $D$ \\
N.A.-1 & 7.6 .74 & 0.043 & 0.490 & 0.431 & 0.035 & -0.210 & 0.854 \\
& 2.7 .74 & 0.040 & 0.506 & 0.406 & 0.048 & -0.203 & 0.832 \\
& 9.9 .74 & 0.013 & 0.594 & 0.387 & 0.006 & -0.230 & 0.975 \\
N.A.-2 & $2-7.7 .74$ & 0.018 & 0.379 & 0.566 & 0.036 & -0.214 & 0.922 \\
& 9.9 .74 & 0.027 & 0.378 & 0.588 & 0.008 & -0.222 & 0.969
\end{tabular}


The linkage associations noted at North Appin were common in other populations in the Menangle area. Several populations were fixed for both the $S$ allele of LAP-1 and the $M$ allele of LAP-2. However, exceptions were noted. Population 27 was, for instance, fixed for the $S$ allele at both loci. This latter observation, plus the fact that several populations were polymorphic at only one of the two loci (table 1) provide strong evidence that the LAP-1 and LAP-2 phenotypes were controlled by different loci.

\section{DisCUSSION}

Genetic variation was detected in $D$. carinata populations at 3 of the 16 loci examined. Although the species gene pool was not particularly invariant, local populations were polymorphic on average at only 6.7 per cent of their loci and individuals heterozygous at only $2 \cdot 1$ per cent of their loci. The low heterozygosity of local populations is apparently the result of founder effect coupled with low gene flow. Large gene frequency differences and allelic substitutions were observed among populations at all the polymorphic loci. Inbreeding coefficients at all 3 loci are high. This evidence for limited gene flow is somewhat paradoxical, for it is evident that $D$. carinata rapidly colonizes habitats, as most populations inhabited ponds less than 30 years old. Furthermore, there were relatively few habitats which looked suitable, but lacked Daphnia. This implies that ephippia are transferred into ponds relatively frequently. If so, then new alleles must of ten be introduced into established populations. Yet many $D$. carinata populations were monomorphic at loci that were polymorphic in the region. The maintenance of genetic divergence among populations in the face of repeated ephippial transfer can only be explained if the fate of secondary colonists is very different from that of the first colonist. Interference competition provides a likely basis for such a difference. The first colonist reaches a habitat with abundant resources and its offspring should increase exponentially until the carrying capacity of the environment is reached. The genes carried by this colonist increase in numbers enormously. By contrast secondary colonists will find resources scarce and possibilities for population growth limited. As a result any novel alleles introduced will remain rare and most probably be lost via drift. Because of Daphnia's high intrinsic rate of increase, it would require only a few weeks for the offspring of a single colonist to saturate a pond. If colonization is rare on this time scale and if interference competition occurs among conspecific clones, then genetic divergence among Daphnia populations is expected. In fact there is good reason to expect strong competition among clones. Prior studies have shown that considerable resource overlap and stong interference competition occurs even among different Daphnia species (Hebert 1977b). This model, to account for the genetic divergence of local Daphnia populations, is similar to one proposed by Platt and Weis (1978) to account for differences in the species composition of the fugitive plant communities growing on badger mounds. They werè able to show that the occupancy of any particular mound was largely determined by chance-the species whose seed first arrived on a mound was able to exclude all later colonists.

The hypothesis that the genetic divergence of Daphnia populations is maintained by competitive interactions which preclude the numerical increase of secondary colonists is testable. In particular it should be possible 
to insert a new allele into an established population by introducing a large number of colonists carrying it. If the model is correct, then this new allele should remain in the population. On the other hand, if selection was responsible for its initial absence, one would expect a rapid elimination of the introduced allele.

Genotypic frequencies in populations of $D$. carinata were for the most part in good agreement with Hardy-Weinberg expectations. Temporal studies failed to reveal any major shifts in genotypic frequencies during a single year. In both these regards populations of $D$. carinata resemble those of $D$. magna found in intermittent habitats. The $D$. carinata populations inhabited permanent ponds, but populations died out during the summerthe presence of water did not ensure continued parthenogenetic reproduction. The populations of $D$. carinata did show one difference from intermittent populations of $D$. magna. Temporal surveys of genotypic frequencies showed annual shifts in gene frequencies, whereas in D. magna gene frequencies were stable.

Strong linkage disequilibrium was noted between the two polymorphic LAP loci in the North Appin populations. This disequilibrium is most simply explained by assuming that the loci are tightly linked and that the populations derive from a single founder (Hill and Robertson, 1968; Sved, 1968; Ohta and Kimura, 1969). If the populations were derived from a founder heterozygous at both LAP loci, the initial coefficient of disequilibrium would be $0 \cdot 25$. As $D$. carinata has only a single sexual generation each year, it would require 20 years to reduce the disequilibrium to its current value $(\simeq 0 \cdot 22)$, if the loci were 0.5 map units apart $\left(D_{t}=\right.$ $\left.(1-R)^{t} D_{0}\right)$. The apparent linkage of the LAP loci is compatible with their origin via tandem duplication and subsequent genetic divergence. Roberts and Baker (1973) have described a rather similar instance of linkage disequilibrium between four esterase loci in Drosophila montana. Unfortunately, determination of the map distance between the LAP loci in $D$. carinata awaits the development of techniques allowing the production and hatching of large numbers of sexual eggs. If such breeding studies indicate that the LAP loci are not tightly linked, then selection must be involved in maintaining the disequilibrium observed in the North Appin populations. In this regard it is worth noting that disequilibrium became more pronounced in both North Appin populations during the period of parthenogenetic multiplication in 1974.

The results obtained in the present study were for the most part congruent with earlier work on D. magna. Individuals of both species are heterozygous at a smaller percentage of their loci than individuals of most sexually reproducing species. Populations of both species show pronounced microgeographical differentiation which seems to result from founder effect. Finally, in both species, genotypic frequencies in populations regularly refounded from ephippial eggs are in good agreement with Hardy-Weinberg expectations.

\section{REFERENCES}

BAYLy, I. A. E., AND W. D. WILliams. 1973. Inland waters and their ecology. Longmans, London.

BERGER, E., AND J. SUTHERLAND. 1978. Allozyme variation in two natural populations of Daphnia pulex. Heredity, 41, 13-23. 
HEBERT, P. D. N. 1972. Enzyme variability in natural populations of Daphnia magna. Ph.D. thesis, Cambridge University.

HEBERT, P. D. N. 1974 a. Enzyme variability in natural populations of Daphnia magna. II. Genotypic frequencies in permanent populations. Genetics, 77, 323-334.

HEBERT, P. D. N. $1974 b$. Enzyme variability in natural populations of Daphnia magna. III. Genotypic frequencies in intermittent populations. Genetics, 77, 335-341.

HEBERT, P. D. N. 1975. Enzyme variability in natural populations of Daphnia magna. I. Population structure in East Anglia. Evolution 28, 546-556.

HEBERT, P. D. N. 1977a. A revision of the taxonomy of the genus Daphnia (Crustacea, Daphnidae) in southeastern Australia. Aust. J. Zool, 25, 371-398.

HEBERT, P. D. N. 1977b. Niche overlap among species in the Daphnia carinata complex. J. Anim. Ecol., 46, 399-409.

HEBERT, P. D. N., AND T. J. CREASE. 1980. Clonal coexistence in Daphnia pulex Leydig: another planktonic paradox. Science, 207, 1363-1365.

HILL, W. G., AND A. ROBERTSTON. 1968. Linkage disequilibrium in finite populations. Theoret. Appl. Genet., 38, 226-231.

OHTA, T., AND M. KIMURA. 1969. Linkage disequilibrium at steady state determined by random genetic drift and recurrent mutation. Genetics 63, 229-238.

PLATT, W. J. AND I. M. WEIS. 1978. Resource partitioning and competition within a guild of fugitive prairie plants. Am. Nat., 111, 479-513.

ROBERTS, P. M., AND W. K. BAKER. 1973. Frequency distribution and linkage disequilibrium of active and null esterase isozymes in natural populations of Drosophila montana. Am. Nat., 107, 709-726.

RUST, P. F. 1972. On the estimation of gene frequencies through gene counting. Hum. Hered., $22,58-65$.

SMITH, M. Y. 1974. A study of polymorphism in Simocephalus serrulatus. Ph.D. thesis, University of Cincinnati.

SMITH, M. Y., AND A. FRASER. 1976. Polymorphism in a cyclic parthenogenetic species: Simocephalus serrulatus. Genetics, 84, 631-637.

SVED, J. 1968. The stability of linked systems of loci with a small population size. Genetics, 59 , 543-565.

YOUNG, J. P. W. 1979. Enzyme polymorphism and cyclic parthenogenesis in Daphnia magna. I. Selection and clonal diversity. Genetics, 92, 953-970. 